Stoa

Vol. 3, no. 5, 2012, pp. 137-157

ISSN 2007-1868

\title{
MODELOS, EJEMPLARES, REPRESENTACIONES Y LEYES EN LA GENÉTICA CLÁSICA*
}

\author{
Pablo Lorenzano \\ Universidad Nacional de Quilmes \\ Consejo Nacional de Investigaciones \\ Científicas y Técnicas \\ Argentina \\ pablo.lorenzano@gmail.com
}

RESUMEN: Tomando como punto de partida el análisis que realiza Kuhn de los libros de texto y su aplicación al caso de Sinnott y Dunn (1925), en este trabajo se discutirá el problema de la existencia de leyes en la biología. En particular, se mostrará, en consonancia con las propuestas de Darden (1991) y Schaffner (1980, 1986, 1993), la relevancia de los ejemplares, representados diagramática o gráficamente, en el modo en que se lleva a cabo la enseñanzaaprendizaje de dicha teoría y la práctica científica basada en ella, en la medida en que la información contenida tanto en unos como en otras, indispensable para el correcto desarrollo de ese proceso, excede la proporcionada por las "leyes" o "principios" lingüísticamente articulados y presentados en el texto. Sin embargo, se sostiene que ésta se encuentra presente implícitamente en la que, de acuerdo con el concepto estructuralista de ley fundamental y la reconstrucción de la genética presentada por Balzer y Dawe (1990), y posteriormente desarrollada por Balzer y Lorenzano (1997) y Lorenzano (1995, 2000, 2002a), pudiera considerarse la ley fundamental de la genética clásica, la ley de concordancia, claramente identificada en el presente trabajo.

PALABRAS ClAVE: libro de texto · teoría biológica · genética clásica · modelo · ejemplar $\cdot$ diagrama $\cdot$ ley fundamental $\cdot$ ley especial

SUMMARY: Taking as starting point Kuhn's analysis of science textbooks and its application to Sinnott and Dunn's (1925), it will be discussed the problem of the existence of laws in biology. In particular, it will be shown, in accordance

\footnotetext{
* Este trabajo ha sido realizado con la ayuda de los proyectos de investigación PICTR 2006 № 2007 y PICT2007 № 1558 de la Agencia Nacional de Promoción Científica y Tecnológica (Argentina) y FFI2008-01580 y FFI2009-08828 del Ministerio de Ciencia e Innovación (España).
} 
with the proposals of Darden (1991) and Schaffner (1980, 1986, 1993), the relevance of the exemplars, diagrammatically or graphically represented, in the way in which is carried out the teaching and learning process of classical genetics, and the practice based on it, inasmuch as the information contained in them, indispensable for the right development of that process, exceeds the information contained in the "laws" or "principles" linguistically articulated and presented in the textbooks. However, it will be maintained that the information is implicit in the law that according to the structuralist concept of fundamental law and the reconstruction of genetics presented by Balzer and Dawe (1990), and later developed by Balzer and Lorenzano (1997), and Lorenzano (1995, 2000, 2002a) could be considered the fundamental law of classical genetics, the law of matching, clearly identified in this paper.

KEYWORDS: textbook - biological theory · classical genetics · model · exemplar - diagram $\cdot$ fundamental law $\cdot$ special law

\section{El primer libro de texto de genética clásica (en sentido kuhniano)}

Ludwik Fleck (1935) y Thomas Kuhn (1959, 1962/1970) han señalado el importante papel que juegan los libros de texto en la enseñanza de la ciencia. Pero, si bien es Fleck el primero en reconocer que "la iniciación a la ciencia se realiza de acuerdo con métodos pedagógicos especiales" (Fleck 1935, p. 148) a través de los libros de texto, es Kuhn quien, siguiendo a Fleck señala que "[1]a característica más notable de esta educación consiste en que, en grado totalmente desconocido en otros campos, se realiza mediante libros de texto" (Kuhn 1959, p. 228), y realiza un primer análisis de ellos. En dicho análisis, Kuhn introduce por primera vez el término de posiblemente mayor repercusión de su trabajo, el de 'paradigma': "en estos libros aparecen soluciones a problemas concretos que dentro de la profesión se vienen aceptando como paradigmas, y luego se le pide al estudiante que resuelva por sí mismo, con lápiz y papel o bien en el laboratorio, problemas muy parecidos, tanto en método como en sustancia, a los que contiene el libro de texto o a los que se han estudiado en clase. Nada mejor calculado para producir "predisposiciones mentales' o Einstellungen" (Kuhn 1959, p. 229). A través de la familiarización con los ejemplos estandarizados, aceptados o compartidos, de las soluciones a problemas concretos o selectos, o paradigmas, que luego serían llamados "ejemplares" (Kuhn 1962/1970), y del intento de resolver los problemas planteados en el libro de texto o por el profesor en clase, se aprende, de una manera 
no discursiva, a ver qué entes pueblan el universo de la investigación, cuáles son las preguntas que pueden plantearse, cuáles las respuestas admisibles y cuáles los métodos para ponerlas a prueba, y a resolver los problemas o "rompecabezas" novedosos, aunque similares a los anteriores, que surgen en el transcurso de la investigación científica (o "ciencia normal"). "Las definiciones verbales", por su parte, "tienen poco contenido científico cuando se las considera en sí mismas. No son especificaciones lógicas completas del significado (si existen), sino más bien ayudas pedagógicas. Los conceptos científicos que indican sólo obtienen un significado pleno cuando se relacionan, dentro de un texto o de alguna otra presentación sistemática, con otros conceptos científicos, con procedimientos de manipulación y con aplicaciones de paradigmas" (Kuhn 1962/1970, p. 142).

El libro de Sinnott y Dunn (1925) es el primer libro de texto de genética clásica que se ajusta al análisis que realiza Kuhn de los libros de texto (Kuhn 1959, 1962/1970). Este fue un libro especialmente concebido como una introducción a la genética, que "establece los principios esenciales de la genética de una modo tan claro y preciso como fuera posible" (p. xvii), para ser usado en cursos universitarios elementales. En él, además de caracterizar en los capítulos iniciales ("Chapter I. The Science of Genetics" y "Chapter II. Heredity and Variation”) a la genética en términos generales y de ubicarla históricamente -reproduciendo lo que se ha denominado "traditional account" (Olby 1979), "orthodox image" (Bowler 1989) o "historia oficial" (Lorenzano 1995), en donde se elabora un relato acumulativo y lineal-, ${ }^{1}$ se introducen sus conceptos básicos - tales como los de individuos, tanto progenitores como descendientes, su cruza o reproducción sexual, las características de los individuos (o fenotipo) y los factores, factoresunidad o genes de los individuos (o genotipo) que determinan dichas características-, los resultados de cruzamientos híbridos (básicamente, las proporciones fenotípicas 3:1, para los monohíbridos, 9:3:3:1, 9:3:4, 9:7, 12:3:1, 13:3, 15:1, para los dihíbridos, y 27:9:9:9:3:3:3:1, para los trihíbridos, además de las correspondientes a caracteres continuos y a aquellas en donde tiene lugar enlace) y sus "principios" o "leyes"

\footnotetext{
${ }^{1}$ Para un análisis de este relato historiográfico, consúltese, entre otros, Lorenzano (1995, 1997, 2002b, 2006a).
} 
-siendo las principales la de la segregación ${ }^{2}$ y la de la transmisión independiente- $-{ }^{3}$ junto con las soluciones a problemas concretos, los ejemplos compartidos, ejemplares o paradigmas, siempre valiéndose de determinadas representaciones diagramáticas o gráficas (ver figs. 1 y 2), y una serie de problemas para ser resueltos por el estudiante al final de cada capítulo.

\section{Leyes y ejemplares en las teorías biológicas}

Dos son los argumentos más importantes que se han esgrimido en contra de la existencia de leyes en biología; se refieren a su no-universalidad y a su contingencia evolutiva. De acuerdo con el primero de ellos (Smart 1963), las habitualmente consideradas como leyes en biología carecen de la universalidad que se suele requerir de las leyes ("en sentido estricto", según la denominación del propio Smart, o fundamentales, según la elucidación clásica, presente por ejemplo en Hempel y Oppenheim 1948), pues acostumbran conllevar la referencia implícita a entidades particulares y poseer excepciones. Para el segundo (Beatty 1995), que presupone un análisis modal del concepto de ley ("ley natural" o "ley de la naturaleza") en términos de necesidad nómica o natural, elaborando una tesis sostenida por Gould (1989), las generalizaciones del mundo viviente son de dos tipos: o bien "son sólo generalizaciones matemáticas, físicas o químicas (o consecuencias deductivas de generalizaciones matemáticas, físicas o químicas más condiciones iniciales)" (Beatty 1995, p. 46), o bien "generalizaciones distintivamente biológicas” (Beatty 1995, p. 47); si son generalizaciones del primer tipo, éstas no pueden ser consideradas leyes de la biología; mientras que, si son del segundo, éstas describen resultados contingentes de la evolución y,

\footnotetext{
2 "La característica esencial del mecanismo de la segregación, por lo tanto, radica en la circunstancia de que un factor transmitido por los gametos de un padre y su factor contrastante transmitido por los gametos del otro padre, se juntan y coexisten durante una generación en las células de la descendencia híbrida resultante, sin mezclarse ni perder su identidad; y que, cuando tal individuo híbrido produce a su vez sus propias células sexuales, estos dos factores se separan de nuevo completa y limpiamente, o segregan, el uno del otro, cada uno de los nuevos gametos siendo enteramente puro, conteniendo ya sea uno u otro de los factores, pero nunca ambos", Sinnott y Dunn (1925), pp. 51-52.

3 "La combinación particular en que ingresan los factores de cada padre en la planta $F_{1}$ (redondo con amarillo y angular con verde en este caso) no tiene ningún efecto en el modo en que ellos se asocian en los gametos formados por esta planta $F_{1}$. Su distribución es independiente", Sinnott y Dunn (1925), p. 67.
} 
de este modo, carecen de necesidad natural o nómica y por lo tanto no deberían ser consideradas leyes de la naturaleza. ${ }^{4}$

Una estrategia posible en contra de la primera de las argumentaciones consiste en cuestionar el análisis que Smart realiza de los ejemplos seleccionados. Este camino es seguido, por ejemplo, por Ruse (1970) y Munson (1975).

Otra estrategia utilizada para defender la existencia de leyes o principios en biología -o de enunciados que, no ajustándose a la elucidación clásica del concepto de ley, cumplen en la biología roles equivalentes a los que tradicionalmente se les adjudican a las leyes, como por ejemplo el de ser explicativas- consiste en distinguir dos tipos de generalizaciones: las empíricas -eventualmente no universales y contingentes, o de necesidad nómica limitada- y las no-empíricas -pero explicativas-, y en sostener que al menos algunas (de las) leyes biológicas (más fundamentales) o principios son del segundo tipo. Esta es la estrategia seguida por autores como Brandon (1978, 1997), Sober (1984, 1993, 1997) y Elgin (2003). ${ }^{5}$

Por otro lado, algunos autores, aceptando dichas argumentaciones, han señalado que, debido a la ausencia de leyes universales y necesarias, por un lado, las teorías de las ciencias biológicas (y/o biomédicas) poseen una estructura particular distinta a la de las teorías físicas y, por el otro, que en la biología y/o en las ciencias biomédicas la familiaridad con un número de ejemplos compartidos o ejemplares es muy importante. Esta es la posición sostenida por autores tales como Darden (1991), para la cual las teorías biológicas consisten en conjuntos de esquemas de resolución de problemas, luego instanciados en ejemplos compartidos o ejemplares, o Schaffner (1980, 1986, 1993), quien sostiene que el mejor modo de caracterizar a dichas teorías es como series de modelos entreniveles, temporales, solapados. ${ }^{6}$

En relación con esta posición, uno podría preguntarse si los esquemas de resolución de problemas, ejemplos compartidos, ejemplares, paradigmas, modelos o diagramas (o gráficos) que los representan que conforman una teoría se encuentran aislados o se relacionan de algún

\footnotetext{
${ }^{4}$ Para una discusión mayor de los argumentos de la no-universalidad y de la contingencia evolutiva, puede consultarse Lorenzano (2001).

${ }^{5}$ Para un análisis de estas dos primeras estrategias, véase Lorenzano (2006b).

${ }^{6}$ Para una discusión de la propuesta de este autor, puede consultarse Lorenzano (por aparecer).
} 
modo. Y si éste fuera el caso, ¿̇cómo se relacionan entre sí, para poder decir que son esquemas de resolución de problemas, ejemplos compartidos, ejemplares, modelos o diagramas que los representan de una y la misma teoría? Podría sostenerse, de manera formalmente análoga a la descripción intensional de "juego" dada por Wittgenstein (1953, SS66 y ss.), mediante el método de los ejemplos paradigmáticos, que entre los distintos paradigmas, ejemplares, ejemplos compartidos, modelos o diagramas que los representan existen similitudes o semejanzas que se cruzan y traslapan, como las que hay entre los distintos miembros de una familia, sin que haya un carácter absolutamente común, e.e., sin que existan propiedades que constituyan condiciones necesarias ni una lista de propiedades que constituyan una condición suficiente para que un sistema empírico sea un paradigma, un ejemplo compartido, un ejemplar o un modelo, aunque siendo similares entre sí, guardando un "aire de familia". Sin embargo, ¿̇en qué sentido habría que sostener que son similares entre sí? No parece que la apariencia de tales sistemas nos proporcione el tipo de similitud deseado; lo importante no es que esos sistemas son similares entre sí aparencialmente, sino más bien estructuralmente: los paradigmas, ejemplos compartidos, ejemplares, modelos o diagramas que los representan de una y la misma teoría poseen la misma estructura (del mismo tipo lógico), pudiendo ser considerados como especificaciones de dicha estructura o esquema más general subyacente. Para precisar esta idea y ver cómo se aplicaría al caso de la genética clásica aquí considerado, utilizaremos la noción estructuralista de ley fundamental. ${ }^{7}$

\section{La noción de ley fundamental en la concepción estructuralista de las teorías}

"Cuando los filósofos discuten leyes de la naturaleza hablan en términos de universalidad y necesidad”, escribe uno de los más importantes representantes de la familia semanticista, a la cual pertenece la concepción estructuralista, Bas van Fraassen (1989, p. 1). Los dos argumentos presentados en contra de la existencia de leyes biológicas se refieren precisamente a su falta de universalidad y necesidad. Sin embargo, con estos criterios parece que no sólo deberían ser descartadas como tales

${ }^{7}$ Véase Balzer, Moulines y Sneed (1987) para una presentación completa o Díez y Lorenzano (2002) para una presentación sucinta de esta concepción metateórica. 
las leyes biológicas, sino también las más respetables leyes físicas. De hecho, debido a la falta de criterios no problemáticos para las leyes de la naturaleza, van Fraassen (1989) propone que dispensemos de esa categoría. Su crítica al concepto de necesidad natural o nómica y su consecuente escepticismo respecto de la noción de ley de la naturaleza es compartido por otros autores, tales como Swartz (1995). Aceptar esto, sin embargo, no implica para ellos que no haya ecuaciones fundamentales o principios básicos de teorías que de hecho estructuren la práctica científica real; excepto que éstas, en oposición a las leyes de la naturaleza, ${ }^{8}$ son concebidas como leyes científicas (Swartz 1995) o leyes de los modelos (van Fraassen 1989, 1993). Tales leyes no son concebidas como regularidades empíricas que gobiernen el mundo natural que nos rodea, independientemente de si los seres inteligentes poseen o no conocimiento de esas regularidades o de si ha sido desarrollada una representación simbólica apropiada o no para al menos algunas de esas regularidades, sino como creaciones humanas, e.e., como regularidades del mundo natural (o, mejor aún, del mundo modelado) conocidas por nosotros y que han sido puestas en formas simbólicas apropiadas y han sido adoptadas en nuestro esfuerzo colectivo por explicar, predecir y controlar dicho mundo. En lo que sigue, cuando hablemos de leyes, lo haremos para referirnos a las leyes científicas o de la ciencia y, correspondientemente, al de las leyes de de la biología o de las ciencias biológicas.

A pesar de los sucesivos y renovados esfuerzos realizados, sin embargo, todavía no disponemos de un concepto satisfactorio de ley científica, e.e. de un conjunto adecuado de condiciones necesarias y suficientes precisas como criterio para que un enunciado sea considerado una "ley”. ${ }^{9}$ Más aún, "[e]s probable que ningún conjunto tal de condiciones pueda ser alguna vez encontrado que apareciera como satisfactorio para todos, ya que la noción de ley es una noción fuertemente histórica, dependiente de la disciplina” (Balzer, Moulines y Sneed 1987, p. 19).

Dentro de la tradición estructuralista, cuando de manera por lo general dispersa, pero recurrente, se trata el tema de las leyes, ${ }^{10}$ las dis-

\footnotetext{
${ }^{8}$ Véase Weinert (1995) para una discusión en torno al concepto de ley de la naturaleza.

${ }^{9}$ Véase Stegmüller (1983) y Salmon (1989) para un análisis de las dificultades con las que se enfrenta la elucidación clásica del concepto de ley científica.

${ }^{10}$ Véase p.e. Balzer (1979), Balzer, Moulines y Sneed (1987), Bartelborth (1988), Moulines (1982, 1991), Sneed (1971), Stegmüller (1973, 1976, 1978, 1979a, 1979b, 1986).
} 
cusiones, aun desde sus comienzos con Sneed (1971), si bien no con esa terminología, se centran en aquellas que, a partir de Stegmüller (1973), son denominadas "leyes fundamentales" de una teoría. ${ }^{11} \mathrm{Y}$ cuando se discuten los criterios para que un enunciado sea considerado como una ley fundamental, a partir de asumir que, a pesar de los sucesivos y renovados esfuerzos realizados en ese sentido, todavía no disponemos de un conjunto adecuado de condiciones necesarias y suficientes precisas como criterio para que un enunciado sea considerado una "ley (científica)" 12 y que, más aún, "[e]s probable que ningún conjunto tal de condiciones pueda ser alguna vez encontrado que apareciera como satisfactorio para todos, ya que la noción de ley es una noción fuertemente histórica, dependiente de la disciplina” (Balzer, Moulines y Sneed 1987, p. 19), se tiende a hablar más bien de "condiciones necesarias" (Stegmüller 1986), de "condiciones necesarias débiles" (Balzer, Moulines y Sneed 1987) o, mejor aún, sólo de «síntomas», algunos incluso formalizables" (Moulines 1991).

Los cuatro criterios que se suelen mencionar como condiciones necesarias, condiciones necesarias débiles o "síntomas" para que un enunciado sea considerado una ley fundamental son los siguientes: 1) su carácter arracimado o sinóptico; 2) que valga en todas las aplicaciones intencionales; 3) su carácter cuasi-vacuo; y 4) su papel sistematizador. ${ }^{13}$ De acuerdo con el primero de los criterios, su carácter sinóptico, que ya había hecho aparición en la literatura estructuralista en Stegmüller (1979a, 1979b, 1986) y que es igualmente recogido en Balzer, Moulines y Sneed (1987) y en Moulines (1991), en su versión más fuerte, "cualquier formulación correcta de la ley debería incluir necesariamente todos los términos relacionales (e implícitamente también todos los conjuntos básicos) y, por tanto, en definitiva, todos los conceptos fundamentales que caracterizan dicha teoría” (Moulines 1991, p. 234), mientras que, en sus formulaciones más débiles, no se exige que en

\footnotetext{
${ }^{11}$ Las expresiones "ley fundamental" y "ley especial" no se utilizan aquí en el sentido de Fodor (1974, 1991), como refiriéndose a leyes pertenecientes a distintos tipos de ciencias, fundamental o básica las primeras y especiales la segunda, sino en el sentido de la concepción estructuralista, es decir, como denotando distintos tipos de leyes de una y la misma teoría. Y como se verá más adelante, la expresión "ley fundamental" tampoco es usada en el sentido de la elucidación clásica aludida más arriba.

${ }^{12}$ Véase Stegmüller (1983) y Salmon (1989) para un análisis de las dificultades con las que se enfrenta la elucidación clásica del concepto de ley científica.

${ }^{13}$ Para una discusión más extensa de estos cuatro citerios, véase Lorenzano (2006b, 2008a).
} 
las leyes fundamentales ocurran todos los conceptos fundamentales, sino sólo "varias de las magnitudes" (Stegmüller 1986, p. 23), "diversas funciones" (Stegmüller 1986, p. 93), "posiblemente muchos conceptos teóricos y no-teóricos” (Stegmüller 1986, p. 386), "casi todos” (Balzer, Moulines y Sneed 1987, p. 19) o "al menos dos" (Stegmüller 1986, p. 151).

El segundo de los criterios para que un enunciado sea considerado como una ley fundamental recogido en Stegmüller (1986) de manera explícita, pero que de algún modo u otro se encuentra presente en toda la literatura estructuralista, "es la validez en todas las aplicaciones intencionales" (p. 93). De acuerdo con este criterio, no es necesario que las leyes fundamentales de las teorías posean un alcance ilimitado, se apliquen en todo tiempo y lugar y tengan como universo de discurso algo así como una "gran aplicación", que constituye un modelo único o "cósmico" (Stegmüller 1979b, Mosterín 1984), sino que basta que se apliquen a sistemas empíricos parciales y bien delimitados (el conjunto de aplicaciones intencionales).

El tercero de los criterios -el carácter cuasi-vacuo (empíricamente) de las leyes fundamentales- se refiere al hecho de que éstas son altamente abstractas, esquemáticas, lo suficientemente vacías y con ocurrencia esencial de términos $T$-teóricos como para resistir cualquier posible refutación (Moulines 1991), ${ }^{14}$ pero que, sin embargo, adquieren contenido empírico específico (y la posibilidad de ser contrastadas) a través de un proceso no-deductivo conocido con el nombre de "especialización". Dicho proceso, por medio del cual se obtienen las leyes más específicas, llamadas "especiales", a partir de una(s pocas) ley(es) fundamental(es) de una teoría, consiste en la introducción de ulteriores restricciones, constricciones o especificaciones a (algunos de los componentes de) dicha(s) ley(es), de forma tal de irse concretando progresivamente en direcciones diversas, hasta desembocar finalmente en las llamadas "especializaciones terminales", en donde todos sus componentes se encuentran especificados. ${ }^{15} \mathrm{El}$ último de los "sínto-

\footnotetext{
${ }^{14}$ Para un intento de dar cuenta del carácter cuasi-vacuo de las leyes fundamentales y de su condición de empíricamente irrestrictas, a través del análisis de su forma lógica y del tipo de conceptos que allí ocurren, véase Moulines (1982).

${ }^{15} \mathrm{En}$ caso de que las especificaciones introducidas resulten ser las apropiadas, se dice que las aplicaciones pretendidas devienen "exitosas". Mientras que en general es a través de las llamadas "aserciones (o afirmaciones) empíricas" asociadas a los distintos elementos teóricos
} 
mas" - el papel sistematizador de las leyes fundamentales- podría entenderse como estableciendo que éstas posibilitan incluir dentro de una misma teoría diversas aplicaciones a distintos sistemas empíricos, al proveer una guía y un marco conceptual para la formulación de otras leyes (las denominadas "especiales") (Moulines 1991) que, como vimos más arriba, introducen restricciones adicionales respecto de las leyes fundamentales y se aplican así a los sistemas empíricos en particular. Merced entonces al proceso de "especialización", que estructura a las teorías de un modo fuertemente jerárquico, y a la obtención de aplicaciones "exitosas", se consiguen integrar los distintos sistemas empíricos, "modelos" o "ejemplares" bajo una misma conceptualización, en donde la(s) ley(es) fundamental(es) ocupan un lugar central.

\section{La ley fundamental de la genética clásica}

Ninguna de las denominadas "leyes de Mendel", ni la ley de la segregación ni la ley de la transmisión independiente, identificadas en Sinnott y Dunn (1925) como los "principios" básicos de la genética, ${ }^{16}$ son lo

que conforman una red teórica que se puede establecer una conexión entre este enfoque "semántico" o "modelo-teórico" y el enfoque clásico ("enunciativo"o "sintáctico"), son las "aserciones empíricas" asociadas a las leyes especiales que se encuentran en ese nivel las que en todo caso podrían ser sometidas al análisis tradicional de la contrastación, y de la consiguiente evaluación, de hipótesis.

${ }^{16}$ La ley que formula Mendel -"la ley de desarrollo/evolución encontrada para Pisum" (Mendel 1865, p. 50), que se descompone en "la ley de la combinación simple de las características" ("Si $A$ denota una de las características constantes, por ejemplo la dominante; $a$ denota la recesiva y $A a$ la forma híbrida, así da la expresión: $A+2 A a+a$ la serie de desarrollo/evolución para los descendientes de los híbridos para dos características diferenciales", Mendel 1865, pp. 34-35) y en "la ley de la combinación de las características diferenciales" ("los descendientes de los hibridos en los cuales se han unido varias características esencialmente diferentes, presentan los miembros de una serie combinatoria en la que se han unido las series de desarrollo para dos características diferenciales. Con esto se demuestra, al mismo tiempo, que el comportamiento de cada dos (tipos de) características diferenciales es independiente en la unión híbrida de cualesquiera otras diferencias en las plantas parentales", Mendel 1865, p. 40)- no se identifica con las leyes que más tarde llevan su nombre: Mendel plantea estas leyes en términos de las características mismas, o sea, en términos de lo que a partir de Johannsen (1909) sería denominado "fenotipo", y no en términos de "genes" o "factores", como suele hacerse en la presentación hoy habitual de las llamadas "leyes de Mendel". Además, Mendel intenta fundamentar y explicar esta ley, que rige el comportamiento de los denominados "híbridos variables" - entre los que se encuentran las arvejas, del género Pisum, con las que realizó gran parte de sus experimentos-, mediante la relación entre la producción y comportamiento de las células germinales y polínicas y el de las formas (o características) constantes (Mendel 1865, p. 32) y, en última instancia, la constitución y agrupamiento de lo que denomina "elementos" (Mendel 1865, p. 58) o "elementos celulares" (Mendel 1865, p. 60). Ésta es una segunda diferencia 
suficientemente esquemáticas y generales, de forma tal no sólo de conectar todos, o casi todos, los términos de la teoría sino de ser aceptada por la comunidad científica respectiva, la de los genetistas, como válidas en todas las aplicaciones y como proporcionando un marco conceptual que permita formular todas las leyes especiales de la genética clásica. Estas leyes, por lo tanto, no pueden ser consideradas como leyes fundamentales de la genética. Y lo que parecería aún peor, hasta ahora los genetistas no han formulado tal ley, es decir, ella no puede ser "observada" en la literatura de la genética. ${ }^{17}$

Sin embargo, la reconstrucción de la genética clásica realizada dentro del marco de la concepción estructuralista de las teorías ${ }^{18}$ sugiere la existencia de una ley fundamental de la genética, basándose en razones sistemáticas, haciendo explícito lo solamente implícito.

La genética clásica es una teoría acerca de la transmisión hereditaria, en la cual se sigue la herencia de diversos rasgos, caracteres o características (fenotipo) de generación en generación de individuos, se disciernen razones numéricas (frecuencias relativas) en la distribución de esas características en la descendencia. La ley fundamental de-

importante entre la(s) ley(es) que propone Mendel y las que le atribuyen y llevan su nombre: aquélla(s) no sólo viene(n) formulada(s) en términos de las características mismas y no de aquellas entidades responsables por la aparición de dichas características ("factores", "genes" o "elementos"), sino que, de acuerdo con él, aquélla(s) requiere(n) fundamentación y explicación, en tanto que las que se le atribuyen a él, no requieren explicación, sino que son ellas mismas consideradas explicativas. Además, los elementos de los que nos habla Mendel no se identifican con los genes, factores, alelos o factores alelos o alélicos de la genética "clásica” (para un análisis más extenso ver p.e. Lorenzano 2008b). Por otro lado, en los tempranos días del "mendelismo", no se acostumbraba separar explícitamente la hoy denominada "ley de la transmisión independiente", o "segunda ley de Mendel", de la "ley de la segregación", o "primera ley de Mendel". Uno sus llamados "redescubridores", Hugo de Vries, fue el primero en hablar de la "ley de la segregación de los híbridos" ("loi de disjonction des hybrides" en francés y "Spaltungsgesetz der Bastarde" en alemán) como descubierta por Mendel. Sin embargo, él hablaba de segregación de caracteres - "caractères" en francés y "Merkmale" en alemán- y no de factores o genes, debido a que en ese tiempo no estaba del todo clara la distinción entre caracteres y rasgos, por un lado, y factores o genes, por el otro (véase Vries 1900). Otro de los llamados "redescubridores", Carl Correns, utiliza la expresión "regla de Mendel" ("Mendels Regel" en alemán) para referirse tanto a la "ley de segregación" de De Vries como a lo que llegó a ser más tarde la "segunda ley de Mendel" (ver Correns 1900). El primero en usar el término "transmisión independiente" fue Thomas Hunt Morgan (Morgan, 1913). Recién en 1916, Morgan habló explícitamente de dos leyes, la ley de la segregación y la ley de la transmisión independiente de los genes y le atribuyó su descubrimiento a Mendel, refiriéndose a ellas como "primera ley de Mendel" y "segunda ley de Mendel”, respectivamente (véase Morgan 1916).

${ }^{17}$ Sobre esto acuerdan autores tales como Kitcher (1984) y Darden (1996).

${ }^{18}$ Balzer y Dawe (1990), Balzer y Lorenzano (2000) y Lorenzano (1995, 2000, 2002a). 
termina el modo de "dar cuenta" de esas distribuciones, postulando la existencia de tipos y números apropiados de factores o genes (genotipo) en los individuos, la forma en que se distribuyen los genes parentales en la descendencia y el modo en que se relacionan los genes con las características, y estableciendo que, dados dos progenitores -con ciertas características (fenotipo) y cierto número de genes (genotipo) y en donde se da cierta relación entre características y genes-, que se cruzan y dan lugar a la descendencia - que posee ciertas características con cierto número de genes, y en donde se da cierta relación entre características y genes-, tiene lugar cierta coincidencia o concordancia (ya sea exacta -o ideal- o aproximada) ${ }^{19}$ entre las distribuciones de las características (frecuencias relativas) y las distribuciones de genes postuladas teóricamente (probabilidades esperadas o teóricas), dadas determinadas relaciones entre genes y características (de expresión de los genes, a partir de distintos grados de dominancia o epistasis). Esta ley, que a falta de mejor nombre denominaremos "ley de concordancia", aunque no formulada explícitamente en la literatura genética, subyace de manera implícita a las formulaciones habituales de esta teoría, sistematizándola, dotando de sentido a la práctica de los genetistas y unificando los esquemas de resolución de problemas, paradigmas, ejemplos compartidos, ejemplares, modelos o diagramas que los representan bajo una y la misma teoría. Dichos modelos pueden ser concebidos como estructuras del siguiente tipo $\langle J, P, G, A P P, M A T, D I S T, D E T, C O M B\rangle$-donde $J$ representa el conjunto de individuos (progenitores y descendientes), $P$ el conjunto de las características (o fenotipo), $G$ el conjunto de los factores o genes (genotipo), APP una función que le asigna a los individuos su apariencia o fenotipo, MAT una función de cruza que le asigna a dos padres cualesquiera su descendencia, DIST las frecuencias relativas de las características observadas en la descendencia, $D E T$ las relaciones postuladas entre los genes y las características y $C O M B$ las distribuciones de probabilidad de los genes en la descendencia, que satisfacen la ley de concordancia. Expresado de un modo más formal, ésta es-

${ }^{19}$ Idealmente exacta, en el caso en que no se consideren los rasgos de aproximación que la genética contiene al igual que prácticamente todas las teorías empíricas, o bien sólo aproximada, de forma tal que, de acuerdo a algún procedimiento estadístico, por ejemplo, las distancias entre los coeficientes que representan una distribución teórica y los de las frecuencias relativas no rebasen una $\varepsilon$ dada. 
tablece que si $x=\langle J, P, G, A P P, M A T, D I S T, D E T, C O M B\rangle$, entonces x es un modelo de la genética clásica si y sólo si para toda $i, i^{\prime} \in J$ tal que MATOR está definida para $\left\langle i, i^{\prime}\right\rangle$ y para toda $\gamma, \gamma^{\prime} \in G$ tal que $\operatorname{DET}(\gamma)=\operatorname{APP}(i)$ y $\operatorname{DET}\left(\gamma^{\prime}\right)=\operatorname{APP}\left(i^{\prime}\right)$ vale que: $\operatorname{COMB}\left(\gamma, \gamma^{\prime}\right)=$ $\operatorname{DIST}\left(\operatorname{DET}(\gamma), \operatorname{DET}\left(\gamma^{\prime}\right)\right){ }^{20}$

Es fácil ver que en la propuesta ley de concordancia podemos identificar los elementos presentes en las leyes fundamentales señalados en la sección anterior.

En primer lugar, la ley de concordancia se distingue como una ley sinóptica, al conectar de un modo inseparable los términos más importantes de la genética en una "gran" fórmula. Allí figuran tanto los propios o distintivos de la genética, los genético-teóricos -el conjunto de los factores o genes (genotipo), las distribuciones de probabilidad de los genes en la descendencia y las relaciones postuladas entre los genes y las características- como los que no lo son, los genético-noteóricos, más accesibles empíricamente -los individuos (progenitores y descendientes), el conjunto de las características, la asignación de características a los individuos y de descendientes a los progenitores y las frecuencias relativas de las características observadas en la descendencia.

Por otro lado, la ley de concordancia es altamente esquemática y general, y posee tan poco contenido empírico que resulta irrefutable (carácter "cuasi-vacuo"). Pues, si la frecuencia relativa de las características se determina empíricamente y la distribución de los genes se postula hipotéticamente, chequear que los coeficientes en la distribución de características y de genes en la descendencia son (aproximadamente) iguales, sin introducir restricciones adicionales de ningún tipo,

${ }^{20}$ La genética clásica, al igual que sucede con las demás teorías científicas, no es una entidad aislada, sino que se encuentra esencialmente vinculada con otras teorías; en particular, se halla relacionada con la teoría celular, de modo tal que los factores (o genes) se suponen en o sobre los cromosomas celulares, transmitiéndose de la generación parental a la descendencia a través de las células sexuales (o gametos). Es merced a este vínculo entre la genética y la teoría celular que, en las presentaciones habituales (lingüísticas o gráficas) de la primera de las teorías, aparecen términos propios de la última de ellas, tales como el de 'gametos'. Por razones de simplicidad y limitaciones de espacio, dichos vínculos son dejados de lado en nuestro análisis, razón por la cual tampoco son incorporados los gametos como un conjunto base en las estructuras introducidas más arriba ni mencionados expresamente en la formulación de la ley de coincidencia. (Para un análisis de las "conexiones entrecampos" históricamente cambiantes entre la genética y la citología, véase Darden (1991); para un intento estructuralista de análisis de dichos vínculos, véase Casanueva $(1997,1998)$.) 
consiste en una tarea "de lápiz y papel” y no involucra ningún tipo de trabajo empírico. Sin embargo, como sucede con toda ley fundamental, a pesar de ser ella misma irrefutable, provee un marco conceptual dentro del cual pueden formularse leyes especiales, cada vez más específicas (y de ámbito de aplicación más limitado) hasta llegar a las "terminales", cuyas aserciones empíricas asociadas pueden ser vistas como hipótesis particulares contrastables y, eventualmente, refutables.

Además, podríamos afirmar que esta ley fue aceptada implícitamente como válida en todas las aplicaciones de la teoría por la comunidad de genetistas, que la tuvo como trasfondo general a partir del cual llevar a cabo análisis particulares de las distintas distribuciones de características encontradas, proporcionándoles así una guía para la investigación y el tratamiento específico de esas diversas situaciones empíricas (carácter "sistematizador"). El rol primario de la ley de concordancia fue el de guiar el proceso de especialización, determinando los modos en que ella se debe especificar para obtener leyes especiales. De acuerdo con ella, para dar cuenta de las distribuciones de las características parentales en la descendencia, debe especificarse: a) el número de pares de genes involucrados (uno o más), b) el modo en que se relacionan los genes con las características (dominancia completa o incompleta, codominancia o epistasis), y c) la forma en que se distribuyen los genes parentales en la descendencia (con combinaciones de genes equiprobables o no). Cuando se llevan a cabo estos tres tipos de especificaciones, se obtienen leyes especiales terminales, a cuyas aserciones empíricas asociadas poder dirigir el modus tollens. En caso de que éstas "salgan airosas" de la contrastación, e.e. de que las especificaciones introducidas resulten ser las apropiadas, se dice que las aplicaciones pretendidas devienen "exitosas" y de este manera que los sistemas empíricos devienen "modelos" de la teoría.

En particular, las llamadas "leyes de Mendel", en la medida en que imponen constricciones adicionales a la ley de concordancia, al añadir información específica no contenida en su formulación altamente esquemática, restringiendo así su ámbito de aplicación (como, por ejemplo, al considerar sólo un par de factores alelos o considerar más de uno, pero la misma probabilidad para toda combinación posible de factores parentales), pueden ser obtenidas a partir de la ley fundamental mediante especialización y deben así ser consideradas "leyes 
especiales" de la genética clásica, aun cuando no "especializaciones terminales". ${ }^{21}$ En sus representaciones diagramáticas o gráficas (figs. 1 y 2), sin embargo, aparecen todos los términos que ocurren en ellas, aunque instanciados, de forma tal que lo que tenemos ante nosotros es de hecho la solución a un problema concreto, un ejemplo compartido, un ejemplar o paradigma. Así, plantas de arvejas son los individuos, el color de las flores (coloreadas o blancas) las características, en la fig. 1, y el color (amarillo o verde) y forma de las semillas (redonda o angular), en la fig. 2. Éstas $\left(P_{1}\right)$ se reproducen sexualmente mediante cruzamiento, dejando descendencia $\left(F_{1}\right)$, que posee la apariencia de una de las plantas parentales (con flores coloreadas en la fig. 1 y con semillas amarillas y redondas en la fig. 2). Ésta se autofecunda, dando lugar a una segunda generación $\left(F_{2}\right)$, en donde las características se dan en las proporciones 3:1 (coloreadas respecto de blancas), en el primer caso, y 9:3:3:1 (amarillas y redondas, amarillas y angulares, verdes y redondas y verdes y angulares, respectivamente), en el segundo. Además, se introducen pares de factores (uno - CC o cc- en las plantas parentales de la fig. 1 y dos - YYRR o yyrr- en las de la fig. 2) que determinan la apariencia de los individuos y que muestran la dominancia completa de uno de los factores sobre el otro. Por otra parte, durante la formación de las células sexuales (gametos de $P_{1}$ ) a partir de las cuales se formarán los individuos de la descendencia se reduce a la mitad el número de factores presente en cada par, de forma tal que, cuando se lleva a cabo la fecundación, la descendencia contendrá nuevamente el par completo, pero formado con un factor de cada uno de los individuos parentales. Cuando dicha descendencia se autofecunde, luego de formar células sexuales (gametos de $F_{1}$ ) que transportan los factores, se obtendrán en la siguiente generación todas las combinaciones posibles de factores con la misma probabilidad, de modo tal que, habida cuenta de la dominancia completa de un factor sobre el otro, coinciden con las proporciones fenotípicas 3:1 y 9:3:3:1 y así las explica.

\section{Observaciones finales}

En este trabajo, partiendo de la consideración del primer libro de texto de genética clásica en sentido kuhniano, fue discutido el problema de

\footnotetext{
${ }^{21}$ Para una formulación explícita de las diferentes especializaciones que abarcan la totalidad
} de la red teórica de la genética clásica, véase Lorenzano (1995). 

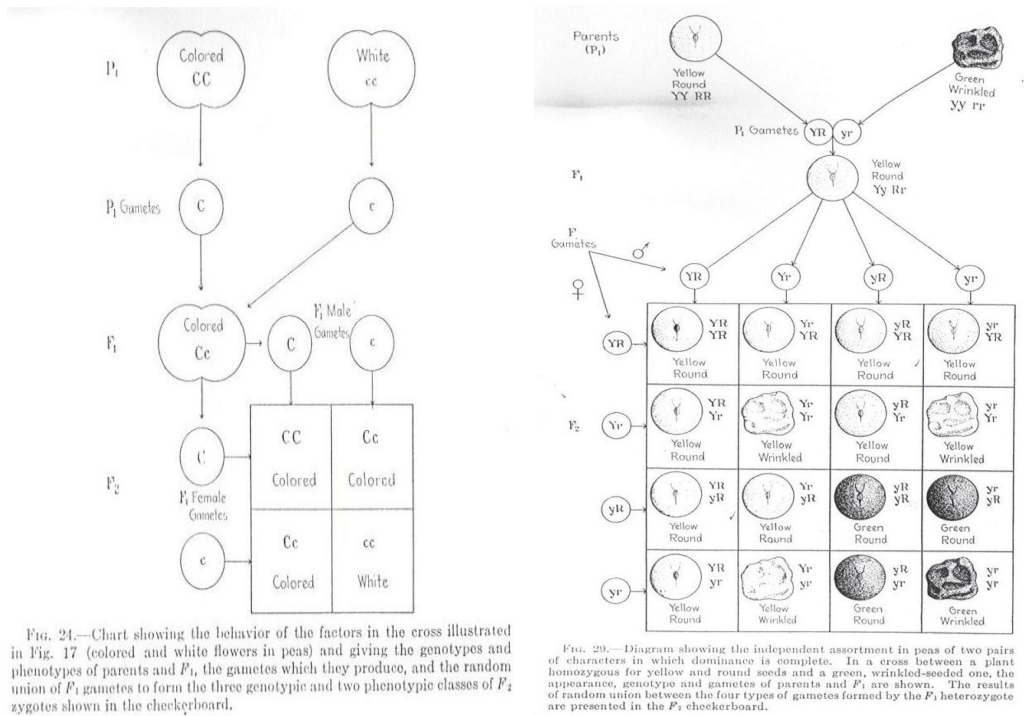

Izquierda: Representación de la ley de segregación (Sinnot y Dunn, p. 53). Derecha: Representación de la ley de la transmisión independiente (Sinnot y Dunn, p. 60).

la existencia de leyes fundamentales en la biología. En primer lugar, se consideró el hecho de que, en los libros de texto de genética, los esquemas de resolución de problemas, ejemplos compartidos, ejemplares, paradigmas, modelos o diagramas que los representan ocupan un lugar central, "transmitiendo" mayor información ("diciendo más") que la contenida en la contraparte formulada lingüísticamente en los libros de texto como "principios" o "leyes", y, de este modo, posibilitando a los estudiantes el aprendizaje del campo en cuestión, a través de la familiarización con ellos y de la subsiguiente resolución de los problemas que allí se plantean. En segundo lugar, se intentó precisar la idea de que los distintos esquemas de resolución de problemas, ejemplos compartidos, ejemplares, paradigmas, modelos o diagramas que los representan de una y la misma teoría poseen la misma estructura (del mismo tipo lógico), pudiendo ser concebidos como especificaciones de dicha estructura o esquema más general subyacente. Para ello, se introdujo el concepto estructuralista de ley fundamental. Basado en él, fue identificada la ley fundamental de la genética clásica, a saber: la ley 
de concordancia, que ejemplifica todas las condiciones necesarias débiles o sintomas considerados de acuerdo con dicho concepto, y se señaló que las presentadas en los libros de texto como los principios básicos de la genética clásica, las llamadas "leyes de Mendel", constituyen leyes que se obtienen mediante "especialización" de la ley fundamental. La afirmación anterior contrasta con aquellas según las cuales en la biología en general y en la genética en particular no pueden encontrarse leyes fundamentales, aun cuando la mencionada ley no se encuentre formulada explícitamente de manera lingüística en los libros de texto, sino sólo implícitamente, pero estructurando la práctica de los genetistas, así como su enseñanza-aprendizaje. De este modo, además, fue mostrado que al menos no todas las teorías de las ciencias biológicas (y/o biomédicas) poseen una estructura particular distinta a la de las teorías pertenecientes a la física. Por último, quisiéramos mencionar que la posibilidad de identificar leyes fundamentales en la biología no tiene porqué limitarse a la genética clásica. Sin embargo, considerar esta posibilidad excede los límites del presente trabajo. ${ }^{22}$

\section{Referencias}

Ahumada, J. y P. Morey (eds.), 1997, Selección de trabajos de las VII Jornadas de Epistemología e Historia de la Ciencia, Facultad de Filosofía y Humanidades, Universidad Nacional de Córdoba, Córdoba.

Balzer, W., 1979, "Die epistemologische Rolle des zweiten Newtonschen Axioms”, Philosophia Naturalis, vol. 17, pp. 131-149.

Balzer, W. y C.M. Dawe, 1990, Models for Genetics, Institut für Philosophie, Logik und Wissenschaftstheorie, Munich.

Balzer, W. y P. Lorenzano, 2000, “The Logical Structure of Classical Genetics”, Zeitschrift für allgemeine Wissenschaftstheorie, vol. 31, pp. 243-266.

Balzer, W., C.U. Moulines y J.D. Sneed, 1987, An Architectonic for Science. The Structuralist Program, D. Reidel, Dordrecht.

-(eds.), 2000, Structuralist Knowledge Representation: Paradigmatic Examples, Rodopi, Amsterdam.

Bartelborth, Th., 1988, Eine logische Rekonstruktion der klassischen Elektrodynamik, Peter Lang, Francfort del Meno.

Beatty, J., 1995, “The Evolutionary Contingency Thesis”, en Wolters y Lennox 1995 , pp. 45-81.

Bowler, P., 1989, The Mendelian Revolution, The Athlone Press, Londres.

${ }^{22}$ Para un análisis en esta línea de la ley fundamental de la genética de poblaciones, ver Lorenzano (2008b). 
Correns, C., 1900, "G. Mendels Regel über das Verhalten der Nachkommenschaft der Rassenbastarde”, Berichte der Deutschen Botanischen Gesellschaft, no. 18 , pp. 158-168.

Darden, L., 1991, Theory Change in Science. Strategies from Mendelian Genetics, Oxford University Press, Oxford.

—, 1996, "Essay Review. Generalizations in Biology. Kenneth F. Schaffner, Discovery and Explanations in Biology and Medicine", Studies in History and Philosophy of Science, vol. 27, no. 3, pp. 409-419.

Díez, J.A. y P. Lorenzano, 2002, "La concepción estructuralista en el contexto de la filosofía de la ciencia del siglo XX”, en Díez y Lorenzano 2002, pp. $13-78$.

-, (comps.), 2002, Desarrollos actuales de la metateoría estructuralista: problemas y discusiones, Universidad Nacional de Quilmes_Universidad Autónoma de Zacatecas Universidad Rovira i Virgili, Quilmes/Zacatecas/Barcelona.

Ernst, G. y K.-G. Niebergall (comps.), 2006, Philosophie der Wissenschaft - Wissenschaft der Philosophie. Festschrift für C. Ulises Moulines zum 60. Geburstag, Mentis-Verlag, Paderborn.

Fleck, L., 1935, Entstehung und Entwicklung einer wissenschaftlichen Tatsache. Einfuhrung in die Lehre vom Denskstil und Denkkollektiv, Benno Schwabe und Co., Basel.

Fodor, J., 1974, "Special Sciences (or: the Disunity of Science as a Working Hypothesis)", Synthese, no. 28, pp. 97-116.

—, 1991, "Hedged Laws and Psychological Explanations", Mind, no. 100, pp. 19-33.

Gould, S.J., 1989, Wonderful Life. The Burgess Shale and the Nature of History, W.W. Norton and Company, Nueva York.

Hempel, C.G. y P. Oppenheim, 1948, "Studies in the Logic of Explanation", Philosophy of Science, no. 15, pp. 135-175.

Johannsen, W., 1909, Elemente der exakten Erblichkeitslehre, Gustav Fischer, Jena.

Kitcher, P., 1984, "1953 and All That: A Tale of Two Sciences", The Philosophical Review, no. 93, pp. 335-373.

Kitcher, P. y W.C. Salmon (eds.), 1989, Scientific Explanation, Minnesota Studies in the Philosophy of Science, vol. 13, University of Minnesota Press, Minneapolis.

Kuhn, T.S., 1959, "The Essential Tension: Tradition and Innovation in Scientific Research", en Taylor 1959, pp. 225-239. Reimpreso en Kuhn 1977, pp. 225-239.

— 1977, The Essential Tension. Selected Studies in Scientific Tradition and Change, University of Chicago Press, Chicago.

—, 19621970, The Structure of Scientific Revolutions, University of Chicago Press, $2^{\mathrm{a}}$ ed., Chicago.

Lorenzano, P., 1995, Geschichte und Struktur der klassischen Genetik, Peter Lang, Francfort del Meno. 
— 1997 , "Hacia una nueva interpretación de la obra de Mendel", en Ahumada y Morey 1997, pp. 220-231.

— 2000, "Classical Genetics and the Theory-Net of Genetics", en Balzer, Moulines y Sneed 2000, pp. 251-284.

—, 2001, "On Biological Laws and the Laws of Biological Sciences", Revista Patagónica de Filosofía no. 2, pp. 29-43.

—, 2002a, "La teoría del gen y la red teórica de la genética", en Díez y Lorenzano 2002, pp. 285-330.

_, $2002 \mathrm{~b}$, "Leyes fundamentales, refinamientos y especializaciones: del 'mendelismo' a la 'teoría del gen”, en Lorenzano y Tula Molina 2002, pp. 379296.

— , 2006a, "La emergencia de un programa de investigación en genética", en Lorenzano, Martins y Regner 2006, pp. 333-360.

— , 2006b, "Fundamental Laws and Laws of Biology", en Ernst y Niebergall 2006, pp. 129-155.

—, 2008a, "Lo a priori constitutivo y las leyes (y teorías) científicas", Revista de Filosofía, vol. 33, no. 2, pp. 21-48.

— 2 2008b, "Incomensurabilidad teórica y comparabilidad empírica", Análisis Filosófico, vol. 28, no. 2, pp. 239-279.

—, 2008 c, "Bas van Fraassen y la ley de Hardy-Weinberg: una discusión y desarrollo de su diagnóstico", Principia, vol. 12, no. 2, pp. 121-154.

_- (por aparecer), "Kenneth Schaffner, las teorías de alcance intermedio y la concepción estructuralista de las teorías”, en Peris-Viñé (por aparecer).

Lorenzano, P. y F. Tula Molina (comps.), 2002, Filosofía e Historia de la Ciencia en el Cono Sur, Universidad Nacional de Quilmes, Quilmes.

Lorenzano, P., Martins, L.A.-C.P. y A.C. Regner (eds.), 2006, Ciências da vida: estudos filosóficos e históricos, Filosofia e História da Ciência no Cone Sul, volume 2, Associação de Filosofia e História da Ciência do Cone Sul (AFHIC), Campinas.

Mendel, G., 1865, "Versuche über Pflanzen-Hybriden", Verhandlungen des Naturforschenden Vereins zu Brünn, no. 4, pp. 3-57; reimpreso en Ostwald 1970, pp. 21-64.

Morgan, T.H., 1913, Heredity and Sex, Columbia University Press, Nueva York.

—, 1916, A Critique of the Theory of Evolution, Princeton University Press, Princeton.

Mosterín, J., 1984, Conceptos y teorías en la ciencia, Alianza Editorial, Madrid.

Moulines, C.U., 1991, Pluralidad y recursión, Alianza Editorial, Madrid.

—, 1978a, Exploraciones metacientíficas, Alianza Editorial, Madrid.

—, 1978 b, "Forma y función de los principios-guía en las teorías físicas", en 1978a, pp. 88-107.

Niiniluoto, I. y R. Tuomela (eds.), 1979, The Logic and Epistemology of Scientific Change (Acta Philosophica Fennica no. 30), North-Holland, Ámsterdam. 
Olby, R. (1979), “Mendel No Mendelian?”, History of Science, no. 17, pp. 5372; reimpreso en Olby 1985, pp. 234-258.

-, Origins of Mendelism, The University of Chicago Press, Chicago, $2^{\underline{a}}$ ed. aumentada.

Ostwald, 1970, Ostwalds Klassikern der exakten Wissenschaften, no. 6, Friedrich Vieweg und Sohn, Braunschweig.

Peris-Viñé, L.M. (ed.), (por aparecer) Filosofía de la Ciencia en Iberoamérica: Metateoría estructural, Tecnos, Madrid.

Salmon, W.C., 1989, "Four Decades of Scientific Explanation", en Kitcher y Salmon 1989, pp. 3-219.

Schaffner, K.F., 1980, "Theory Structures in the Biomedical Sciences", The Journal of Medicine and Philosophy, no. 5, pp. 57-97.

— 1986, "Exemplar Reasoning About Biological Models and Diseases: A Relation Between the Philosophy of Medicine and Philosophy of Science", The Journal of Medicine and Philosophy, no. 11, pp. 63-80.

—, 1993, Discovery and Explanations in Biology and Medicine, University of Chicago Press, ChicagoLondres.

Sinnott, E.W. y L.C. Dunn, Principles of Genetics: An Elementary Text, with Problems, McGraw-Hill, New York 1925; $2^{\underline{a}}$ ed., 1932; $3^{\underline{a}}$ ed., 1939; con T. Dobzhansky como co-autor, $4^{\underline{a}}$ ed., 1950; $5^{\underline{a}}$ ed., 1958.

Smart, J.J.C., 1963, Philosophy and Scientific Realism, Routledge and Kegan Paul, Londres.

Sneed, J.D., 1971, The Logical Structure of Mathematical Physics, Reidel, Dordrecht 2aㅡ ed. Revisada 1979.

Stegmüller, W., 1973, Theorienstrukturen und Theoriendynamik, Springer, Heidelberg.

—, 1976, "Eine 'subjektivistische' Variante des Begriffs der physikalischen Theorie”, en Stegmüller 1980, pp. 56-86.

—, (comp.), 1980, Neue Wege der Wissenschaftsphilosophie, Springer, Berlín/Heidelberg/Nueva York.

— 1978, "A Combined Approach to the Dynamics of Theories", Theory and Decision, no. 9, pp. 39-75.

—, 1979a, "The Structuralist View: Survey, Recent Development and Answers to Some Criticisms", en Niiniluoto y Tuomela 1979, pp. 113-129.

—, 1979b, The Structuralist View of Theories, Springer, Berlín.

—, 1983, Erklärung-Begründung-Kausalität, Springer, Berlín/Heidelberg/Nueva York, $2^{\mathrm{a}}$ ed. ampliada y modificada.

—, 1986, Theorie und Erfahrung, Band II, Dritter Halbband, Springer, Berlín/ Heidelberg/Nueva York.

Taylor, C.W. (comp.), 1959, The Third (1959) University of Utah Research Conference on the Identification of Scientific Talent, University of Utah Press, Salt Lake City. 
Vries, H. de, 1900a, "Sur la loi de disjonction des hybrides", Comptes Rendus de l'Académie des Sciences no. 130, pp. 845-847.

—, 1900b, "Das Spaltungsgesetz der Bastarde (Vorläufige Mittheilung)", Berichte der Deutschen Botanischen Gesellschaft, no. 18, pp. 83-90.

Wittgenstein, L., 1953, Philosophische Untersuchungen/Philosophical Investigations, Basil Blackwell, Oxford.

Wolters, G. y J. Lennox (comps.), 1995, Theories and Rationality in the Biological Sciences, The Second Annual Pittsburgh/Konstanz Coloquium in the Philosophy of Science, University of Pittsburgh Press, Pittsburgh. 